\title{
PENGARUH KEPRIBADIAN RIGHT WING AUHTORITARIAN PERSONALITY, RELIGIOUS ORIENTATION DAN IDENTITAS SOSIAL TERHADAP PRASANGKA AGAMA PADA MAHASISWA
}

\author{
Hilman Fauzi \\ Hilmanf9@gmail.com \\ Anggota HIMPSI Provinsi DKI Jakarta
}

\author{
Ima Sri Rahmani \\ Ima.rahmani@uinjkt.ac.id \\ Fakultas Psikologi UIN Syarif \\ Hidayatullah Jakarta
}

\begin{abstract}
The aim of this study is to explore the influence of right wing authoritarian, religious orientation and social identity against religious prejudice on students. By using accidental sampling, 200 participants took part in this research. Some factors are examine in this research, right wing auhtoritarian personality, religious orientation, and social identity. The instrument that are used in this research is Prejudice Scale, Religious Orientation Scale (ROS), and Social Identity Scale. Confirmatory factor analysis (CFA) is used to examine the validity of the scale. Multiple regression analysis is used for data analysis. The result showed that there is significant effect of right wing authoritarian personality, religious orientation, and social identity toward religious prejudice among student as many $17.5 \%$. The result from minor hypotheses test showed that there are three variables that are significantly affect religious prejudice, they are submission, extrinsic and sense of belonging. Overall, it can be concluded that right wing authoritarian personality, religious orientation, and social identity significantly affect religious prejudice. Future research is suggested to explore other variables that might affect religious prejudice.
\end{abstract}

Keyword: religious prejudice, right wing authoritarian personality, religious orientation, social identity.

\begin{abstract}
Abstrak
Penelitian ini bertujuan untuk mengetahui pengaruh kepribadian right wing authoritarian, religious orientation dan identitas sosial terhadap prasangka agama pada mahasiswa. Populasi pada penelitian ini adalah mahasiswa aktif UIN Syarif Hidayatullah Jakarta.. Sampel berjumlah 200 orang yang diambil dengan teknik accidental non-probability. Analisis data menggunakan analisis regresi berganda. Hasil penelitian menunjukkan bahwa terdapat pengaruh yang signifikan kepribadian right wing authoritarian, religious orientation dan identitas sosial terhadap prasangka agama. Hasil uji hipotesis minor menemukan bahwa terdapat tiga variabel yang memengaruhi secara signifikan, yaitu submission, ekstrinsik dan sense of belonging. Sedangkan agression, conventionalism, intrinsik, categorization dan positive attitude tidak signifikan mempengaruhi prasangka agama. Penelitian selanjutnya diharapkan mampu mengembangkan penelitian ini dengan melibatkan variabel lain.
\end{abstract}

Kata Kunci: prasangka agama, kepribadian right wing authoritarian, religious orientation, identitas sosial

Diterima: 16 Januari 2017 Direvisi: 19 Februari 2017 Disetujui: 20 Maret 2017 


\section{PENDAHULUAN}

Prasangka, rasisme dan diskriminasi saat ini masih menjadi masalah di semua negara di dunia. Objek yang menjadi sasaran dari tindakan prasangka biasanya mulai dari warna kulit hingga agama (Denney, 2008). Di Indonesia, masalah prasangka dan diskriminasi menjadi masalah yang masih sering timbul. Sejak reformasi tahun 1998, sudah lebih dari 10.000 orang menjadi korban hanya karena perbedaan agama, paham agama, dan etnis (Ali, 2013).

Konflik yang mengatasnamakan agama ini kemudian memunculkan paradoks dalam studi agama dan prasangka bahwa agama yang mengajarkan cinta dan penerimaan cenderung menghasilkan penganut yang lebih berprasangka dan tidak bertoleransi dari pada yang tidak menganut agama (Jennings, 2014). Konflik agama yang terjadi erat kaitannya dengan prasangka. Prasangka diartikan sebagai setiap sikap, emosi atau perilaku terhadap anggota kelompok, yang langsung atau tidak langsung berimplikasi beberapa negatif atau antipati terhadap suatu kelompok (Brown, 2010). Fenomena prasangka sosial dapat terjadi pada setiap orang dan tanpa disadari. Hal ini menunjukan bahwa proses prasangka sosial terbentuk secara otomatis dan dipengaruhi oleh lingkungan sosial yang mendukung proses terjadinya prasangka sosial (Plous, 2003). Keterkaitan antara prasangka pada sikap tiap individu dalam berinteraksi memiliki kecendrungan yang memungkinkan kelompok manapun dapat menjadi sasaran prasangka.

Berdasarkan penjelasan tersebut, timbul pertanyaan bagaimana peran agama yang dianut seseorang dapat menimbulkan prasangka terhadap seseorang dengan latar belakang yang berbeda. Penelitian sebelumnya menjelaskan responden beragama lebih mungkin untuk mengekspresikan prasangka daripada responden non-agama atau tidak beragama (Streib \& Klein, 2014). Salah satu fenomena di Indonesia, khususnya Jakarta dan sekitarnya yang penulis anggap mampu menjelaskan prasangka agama. Hal tersebut didasari data yang menyebutkan bahwa 95 persen warga Indonesia menyatakan agama sangat penting dalam hidup mereka (Theodorou, 2015).

Penelitian ini bertujuan untuk mengeksplorasi faktor psikologis yang dapat memengaruhi prasangka agama. Dari hasil kajian literatur dan penelitian terdahulu, penulis mendapat bahwa kepribadian right wing authoritarian mempengaruhi prasangka (Altemeyer, 2004; Laythe, Finkel, dan Kirkpatrick, 2005; Altemeyer, 2006; Hogg dan Cooper, 2007; Childs, 2011). Selanjutnya, religious orientation juga dianggap, mampu mempengaruhi prasangka (Allport dan Ross, 1967; Herek, 1987; Francis, Jewell, dan Robbins, 2010), dan identitas sosial mampu memprediksi prasangka (Brown, 1995).

\section{KAJIAN TEORI}

Gordon Allport (1949, dalam Akrami, 2005) menjelaskan dalam bukunya The Nature of Prejudice mendefinisikan prasangka adalah antipati berdasarkan generalisasi yang salah atau tidak fleksibel. Prasangka bisa dirasakan atau diekspresikan. Prasangka bisa diarahkan terhadap suatu kelompok secara keseluruhan atau terhadap seseorang karena merupakan anggota kelompok yang 
dimaksud (Akrami, 2005). Namun, menurut Brown (2010) menjelaskan bahwa prasangka adalah sikap sosial atau keyakinan kognitif yang bersifat merendahkan, pengekspresian emosi negatif, tindakan bermusuhan atau diskriminatif terhadap anggota suatu kelompok yang dihubungkan dengan keanggotaannya dalam kelompok tersebut.

Selanjutnya, Kepribadian Right wing authoratorian muncul terkait dari penelitian Adorno dkk di tahun 1950 yang menjelaskan bahwa authoratorian personality. Berdasarkan kritikan terhadap teori authoritarian personality, Altemeyer di mulai pada tahun 1981 mengkonseptualisasikan dengan membangun dan mengembangkan kembali skala F. Altemeyer mengubah konsep dari authoritarian personality menjadi right wing authoritarian (Altemeyer, 2006). Lebih lanjut Altemeyer (2006) menjelaskan bahwa otoratorian terjadi ketika para pengikut menyerahkan terlalu banyak kekuasaan untuk para pemimpin, kepercayaan yang berlebihan serta memberi mereka terlalu banyak peluang untuk melakukan apapun yang mereka inginkan yang sering merupakan sesuatu yang tidak demokratis, tirani dan brutal. Berdasarkan gagasan tersebut, Altemeyer berpendapat bahwa right wing authoratorian adalah suatu tingkat kepatuhan individu merasa bahwa pihak berwenang harus diikuti (Altemeyer, 2006). Kemudian, kepribadian right wing authoratotian dibagi menjadi tiga dimensi kepribadian yaitu authoratorian submission, authoratorian agression dan conventionalism (Altemeyer, 1996).

Kemudian, religious orientation merupakan Allport dan Ross pada tahun 1967 mengkonseptualisasi pengukuran religious orientation yang menghasilkan hubungan dengan berbagai variabel sosio-psikologis untuk membedakan antara dua orientasi agama yang berbeda yang disebut dengan keagamaan intrinsik dan keagamaan ekstrinsik (Francis, Jewell, \& Robbins, 2010). Religious orientation terbagi menjadi dua dimensi, yaitu orientasi intrinsik melibatkan keagamaan yang terletak didalam orang tersebut, dan orientasi ekstrinsik merupakan motif pribadi yang berada di luar agama itu sendiri atau dengan kata lain menggunakan agama untuk beberapa tujuan non religius (Allport dan Ross, 1967).

Selanjutnya, identitas sosial menurut Tajfel (1978 dalam Feitosa, Salas, dan Salazar, 2012) didefinisikan sebagai pengetahuan individu bahwa individu tersebut milik kelompok sosial tertentu bersama-sama dengan beberapa makna emosional dan nilai individu tersebut dari keanggotaan kelompok. Pada perkembangannya, identitas sosial juga didefinisikan sebagai motivasi yang mendorong individu untuk bergabung dengan kelompok karena kebutuhan mereka untuk peningkatan harga diri dan pengurangan ketidakpastian tentang perasaan, persepsi, dan perilaku masyarakat (Hogg \& Terry, 2000).

\section{METODE PENELITIAN}

\section{Populasi, sampel dan teknik pengambilan sampel}

Populasi dalam penelitian ini adalah mahasiswa Universitas Islam Negeri Syarif Hidayatullah Jakarta. Jumlah sampel yang didapat dalam penelitian ini sebanyak 200 orang. Populasi pada penelitian ini berjumlah 23.161 orang. Namun karena kondisi yang tidak memungkinkan, sehingga pengambilan sampel pada penelitian ini menggunakan teknik accidental non probability sampling. Peneliti mengambil 
data dengan cara menyebar kuesioner secara langsung dengan memilih siapa saja yang sesuai dengan kriteria dan di jumpai untuk di jadikan sampel.

\section{Instrumen penelitian}

Penelitian ini menggunakan empat instrumen untuk mengukur variabel, yaitu:

1. Prasangka diukur menggunakan skala yang dikonstruk Merz dan Pearlin (1957). Penulis mengadaptasi skala tersebut kedalam bahasa indonesia. Skala ini disusun berdasarkan skala likert dengan rentang dari satu hingga empat poin, yaitu dari "1" (sangat tidak setuju) hingga "4" (sangat setuju). Peneliti menggunakan skala likert empat poin karena untuk menghindari kecenderungan jawaban pada skala tengah-tengah dan mempermudah subjek dalam pengisian alat ukur.

2. Kepribadian right wing authoritarian diukur dengan menggunakan skala Right wing Auhtoritarian Scale (RWAs) yang dikonstruk Altemeyer (1996). Namun, peneliti menggunakan alat ukur kepribadian RWAs dari Funke (2005) dengan membagi right wing authoritarian scale menjadi tiga dimensi dan dan dimodifikasi oleh peneliti setelah melakukan studi pendahuluan pada alat ukur tersebut. Respon jawaban yang diberikan mulai dari "1" (sangat tidak setuju) sampai "4" (sangat setuju) dengan menggunakan skala likert.

3. Religious orientation diukur dengan menggunakan skala religious orientation scale (ROS) yang dikembangkan Allport (1967) dengan 21 item. Penulis mengadaptasi skala tersebut kedalam bahasa indonesia. Respon jawaban yang diberikan mulai dari "1" (sangat tidak setuju) sampai "4" (sangat setuju) dengan menggunakan skala likert.

4. Identitas sosial diukur dengan menggunakan skala yang dikembangkan Jennifer Feitosa, Eduardo Salas dan Maritza R. Salazar (2012) dan dimodifikasi oleh peneliti untuk keperluan penelitian ini. Respon jawaban yang diberikan mulai dari "1" (sangat tidak setuju) sampai "4" (sangat setuju) dengan menggunakan skala likert.

\section{HASI PENELITIAN}

Sebagaimana yang telah dipaparkan pada bahasan sebelumnya, bahwa penelitian dilakukan kepada 200 mahasiswa aktif UIN Syarif Hidayatullah Jakarta. Jumlah sampel berdasarkan usia yaitu ramaja akhir (18-40 tahun) sebanyak 94 orang (47\%), dan dewasa awal sebanyak 106 orang (53\%). Kemudian data responden menurut jenis kelamin menunjukkan pria mengungguli dengan jumlah responden sebanyak 113 orang (56.5\%) sedangkan jumlah responden wanita berjumlah 87 orang $(43.5 \%)$.

Berdasarkan yang pendidikan terakhir menunjukkan responden paling banyak adalah lulusan SMA/SMK sebesar 133 orang (66.5\%). Afiliansi responden dengan organisasi kampus didominasi oleh responden yang tidakberafiliasi dengan organisasi kampus dengan jumlah 66 orang (33\%), berafiliasi pada HMI dengan jumlah 64 orang $(32 \%)$, dan responden yang berafiliasi oragnisasi IMM berjumlah 3 orang $(1.5 \%)$. Data responden yang berafiliasi dengan organisasi agama dari empat pilihan organisasi yaitu NU, muhammadiya, HTI dan pilihan lain, NU mendominasi dengan 89 orang 
(44.5\%) sedangkan responden yang berafiliasi dengan HTI didapati dengan jumlah terendah dengan 6 orang (3\%). Data terakhir, ketersetujuan dari responden dengan negara islam, data responden menunjukan dengan 100 orang (50\%) menjawab setuju dengan Negara islam dan 100 orang (50\%) yang lain menjawab tidak setuju dengan negara islam. Adapun gambaran umum subjek penelitian dapat dilihat pada tabel 1 berikut ini.

Tabel. 1

Gambaran Umum Subjek Penelitian

\begin{tabular}{lll}
\hline Sampel Penelitian & Jumlah & Persentase \\
\hline Usia 17-20 (remaja akhir) & 94 & $47 \%$ \\
Usia $\geq 21$ (dewasa awal) & 106 & $53 \%$ \\
Pria & 113 & $56.50 \%$ \\
Wanita & 87 & $43.50 \%$ \\
Pendidikan Sebelumnya & & \\
SMA & 133 & $66.50 \%$ \\
Pesantren & 67 & $33.50 \%$ \\
Afiliasi Organisasi Kampus & & \\
HMI & 64 & $32 \%$ \\
IMM & 3 & $1.50 \%$ \\
LDK & 10 & $5 \%$ \\
PMII & 44 & $22 \%$ \\
KAMI & 13 & $6.50 \%$ \\
Tidak berafiliasi & 66 & $33 \%$ \\
Afiliasi Organisasi Agama & & \\
NU & 89 & $44.50 \%$ \\
Muhammadiyah & 16 & $8 \%$ \\
HTI & 6 & $3 \%$ \\
Lain-Lain & 89 & $44.50 \%$ \\
Apakah anda setuju dengan negara Islam & & \\
Ya & 100 & $50 \%$ \\
Tidak & 100 & $50 \%$ \\
\hline
\end{tabular}

Tabel 2

Statistik Deskriptif dan Kategorisasi Skor Variabel Penelitian ( $N=200)$

\begin{tabular}{|c|c|c|c|c|c|c|c|c|}
\hline & Min & Max & Mean & S. D & Variance & Rendah n & $\begin{array}{l}\text { Sedang } \\
\mathrm{n}(\%)\end{array}$ & $\begin{array}{l}\text { Tinggi } \\
\mathrm{n}(\%)\end{array}$ \\
\hline Prejudice & 34 & 76 & 50 & 9.624 & 92.633 & $44(22)$ & $123(61.5)$ & $33(16.5)$ \\
\hline Aggression & 28 & 66 & 50 & 7.099 & 50.397 & $24(12)$ & $161(80.5)$ & $15(7.5)$ \\
\hline Submission & 27 & 71 & 50 & 7.499 & 56.248 & $18(9)$ & $163(81.5)$ & $19(9.5)$ \\
\hline convensionalism & 24 & 69 & 50 & 7.413 & 54.960 & $15(7.5)$ & $166(83)$ & $19(9.5)$ \\
\hline Ekstrinsik & 18 & 68 & 50 & 8.789 & 77.263 & $21(10.5)$ & $146(73)$ & $33(16.5)$ \\
\hline Intrinsic & 20 & 71 & 50 & 8.766 & 76.845 & $19(9.5)$ & $148(74)$ & $33(16.5)$ \\
\hline categorization & 15 & 74 & 50 & 8.729 & 76.210 & $29(14.5)$ & $149(74.5)$ & $22(11)$ \\
\hline SOB & 23 & 72 & 50 & 8.588 & 73.765 & $32(16)$ & $137(68.5)$ & $31(15.5)$ \\
\hline PA & 20 & 71 & 50 & 8.901 & 79.244 & $19(9.5)$ & $161(80.5)$ & $20(10)$ \\
\hline
\end{tabular}


Selanjutnya, peneliti akan menguji hipotesis penelitian dengan menggunakan teknik analisis berganda dengan bantuan software SPSS 20.0. Langkah pertama, peneliti melihat besaran $R$ square untuk mengetahui berapa persen (\%) varians DV yang dijelaskan oleh IV. Adapun hasilnya dapat dilihat pada tabel 3 berikut ini :

Tabel 3.

Model Summary Analisis Regresi

\begin{tabular}{lllll}
\hline \multicolumn{4}{c}{ Model Summary } \\
\hline Model & $\mathrm{R}$ & R Square & Adjusted R Square & Std. Error of the Estimate \\
1 & $.418^{\mathrm{a}}$ & .173 & .139 & 8.93259 \\
\hline
\end{tabular}

a. Predictors: (Constant), Agression, Submission, Conventionalism,

Ekstrinsik, Intrinsik, Categorization, Sense of Belonging, Positive attitude

Dari tabel 3, dapat dilihat bahwa perolehan $R$-square sebesar 0.173 atau 17.3 $\%$. Artinya proporsi varians dari prasangka yang dapat dijelaskan oleh semua independent variable (submission, agression, conventionalism, ekstrinsik, intrinsik, categorization, sense of belonging, positive attitude adalah sebesar $17.3 \%$, sisanya $82.7 \%$ dipengaruhi oleh variabel lain yang tidak ikut diukur dalam penelitian ini. Langkah kedua adalah menganalisis signifikansi pengaruh dari seluruh variabel independen terhadap variabel dependen yaitu dengan melakukan uji F. Adapun hasil uji $\mathrm{F}$ dapat dilihat pada tabel 4 berikut:

Tabel 4.

Pengaruh Keseluruhan IV terhadap DV

\begin{tabular}{llcllll}
\hline Model & & Sum of Squares & df & Mean Square F & Sig. \\
\hline 1 & Regression & 3193.818 & 8 & 399.227 & 5.003 & $.000^{\mathrm{a}}$ \\
& Residual & 15240.098 & 191 & 79.791 & & \\
& Total & 18433.916 & 199 & & \\
\hline
\end{tabular}

a. Dependent Variable: Prasangka

b. Predictors: (Constant), Agression, Submission, Conventionalism, Ekstrinsik,

Intrinsik, Categorization, Sense of Belonging, Positive attitude

Jika melihat pada kolom signifikansi dapat diketahui bahwa nilai signifikansi adalah 0.000. Apabila menggunakan taraf Sig. $<0,05$, maka hipotesis nol ditolak. Artinya, ada pengaruh yang signifikan dari agression, submission, conventionalism, ekstrinsik, intrinsik, categorization, sense of belonging, dan positive attitude terhadap prasangka.

Langkah selanjutnya adalah melihat koefisien regresi masing-masing variabel independen. Jika nilai Sig. $<0,05$, maka koefisien regresi tersebut signifikan. Artinya bahwa variabel independen tersebut memiliki dampak yang signifikan terhadap prasangka. 
Tabel 5

Koefisien Regresi

\begin{tabular}{|c|c|c|c|c|c|c|}
\hline \multirow{2}{*}{\multicolumn{2}{|c|}{ Model }} & \multirow{2}{*}{$\begin{array}{l}\text { Unstandardized } \\
B\end{array}$} & \multirow{2}{*}{$\begin{array}{l}\text { Coefficients } \\
\text { Std. } \\
\text { Error }\end{array}$} & \multicolumn{3}{|c|}{ Standardized Coefficients } \\
\hline & & & & Beta & $t$ & Sig. \\
\hline 1 & (Constant) & 42.620 & 6.936 & & 6.145 & .000 \\
\hline & Agression & -.133 & .095 & -.098 & -1.408 & .161 \\
\hline & Submission & 306 & .091 & 239 & 3.358 & $.001 *$ \\
\hline & Conventionalism & -.181 & 109 & -.140 & -1.659 & .099 \\
\hline & Ekstrinsik & -.169 & .088 & -.154 & -1.915 & $.057^{*}$ \\
\hline & Intrinsik & -.095 & .085 & -.087 & -1.120 & .264 \\
\hline & Categorization & .092 & .106 & .084 & .871 & .385 \\
\hline & Sob & .239 & .097 & .214 & 2.471 & $.014^{*}$ \\
\hline & $\mathrm{Pa}$ & .088 & .095 & .082 & .932 & .352 \\
\hline
\end{tabular}

Keterangan: tanda $\left.{ }^{*}\right)$ menunjukkan variabel yang signifikan

Dari kolom Sig. pada tabel 5, dapat diketahui variabel independen mana saja yang signifikan pengaruhnya. Jika nilai pada kolom Sig. $<0,05$, maka koefisien regresi yang dihasilkan signifikan pengaruhnya terhadap prasangka dan begitu juga sebaliknya. Dari hasil di atas terdapat tiga koefisien regresi yang signifikan pengaruhnya terhadap prasangka, yaitu submission, ekstrinsik dan sense of belonging, sedangkan sisanya tidak signifikan. Prasangka $=$ $44.363-0.133$ Agression +0.306 Submission -0.181 Conventionalism - 0.169 Ekstrinsik -0.095 Intrinsik +0.092 Categorization +0.239 Sense of Belonging +0.088 Positive Attitude. variabel.

Selanjutnya, penulis menyajikan data priporsi varian masing-masing

Tabel 6.

Proporsi Varians Setiap Variabel Independen

\begin{tabular}{|c|c|c|c|c|c|c|c|c|c|}
\hline \multicolumn{6}{|c|}{ Model Summary } & \multicolumn{4}{|c|}{ Change Statistics } \\
\hline Mode & $\mathbf{R}$ & $\begin{array}{l}\mathrm{R} \\
\text { Square }\end{array}$ & $\begin{array}{l}\text { Adjusted } \\
\text { R Square }\end{array}$ & $\begin{array}{l}\text { Std. Error of } \\
\text { the Estimate }\end{array}$ & $\begin{array}{l}\text { R } \\
\text { Square } \\
\text { Change }\end{array}$ & $\begin{array}{l}\text { Change } \\
\text { F Chan }\end{array}$ & Ifis & $\begin{array}{l}\text { cs } \\
\text { df2 }\end{array}$ & $\begin{array}{l}\text { Sig. F } \\
\text { Change }\end{array}$ \\
\hline 1 & $.077^{\mathrm{a}}$ & .006 & .001 & 9.61995 & .006 & 1.192 & 1 & 198 & .276 \\
\hline 2 & $.252^{b}$ & .064 & .054 & 9.36022 & .058 & 12.141 & 1 & 197 & .001 \\
\hline 3 & $.289^{\mathrm{C}}$ & .083 & .069 & 9.28483 & .020 & 4.212 & 1 & 196 & .041 \\
\hline 4 & $.300^{\mathrm{d}}$ & .090 & .071 & 9.27476 & .007 & 1.426 & 1 & 195 & .234 \\
\hline 5 & $.301{ }^{\mathrm{e}}$ & .091 & .067 & 9.29522 & .001 & .142 & 1 & 194 & .706 \\
\hline 6 & $.372^{1}$ & .138 & .112 & 9.07212 & .048 & 10.659 & 1 & 193 & .001 \\
\hline 7 & $.412^{\mathrm{g}}$ & .169 & .139 & 8.92955 & .031 & 7.212 & 1 & 192 & .008 \\
\hline 8 & $.416^{\mathrm{h}}$ & 173 & 139 & 893259 & 004 & 869 & 1 & 191 & 352 \\
\hline
\end{tabular}

Predictors: (Constant), Agression, Submission, Conventionalism, Ekstrinsik, Intrinsik,

Categorization, Sense of Belonging, Positive attitude 


\section{KESIMPULAN DAN SARAN}

\section{Kesimpulan}

Secara umum dapat diambil dua kesimpulan bahwa terdapat pengaruh kepribadian right wing authoritarian (aggression, submission dan conventionalism), religious orientation (ekstrinsik dan intrinsik), dan identitas sosial (categorization, sense of belonging dan positive attitude) terhadap prasangka agama pada mahasiswa UIN Syarif Hidayatullah Jakarta. Hal ini ini menunjukkan bahwa hipotesis mayor pada penelitian ini tidak ditolak. Selanjutnya, dari delapan variabel yang diuji terdapat tiga variabel yang ditemukan signifikan mempengaruhi prasangka. Ini berarti terdapap tiga hipotesis minor yang diterima. Dengan demikian dapat disimpulkan bahwa prasangka dipengaruhi oleh submission, ekstrinsik dan sense of belonging. Sedangkan, aggression, conventionalism, intrinsik, categorization dan positive attitude tidak signifikan mempengaruhi prasangka, sehingga hipotesis penelitian yang menyatakan terdapat pengaruh signifikan ditolak.

\section{Diskusi}

Berdasarkan hasil penelitian ditemukan bahwa ada pengaruh yang signifikan dari kepribadian right wing authoritarian dalam hal ini dimensi submission terhadap prasangka antar agama pada mahasiswa UIN Syarif Hidayatullah Jakarta. Hasil ini sejalan dengan penelitian yang dilakukan oleh Mcfarlan dan Adelson pada tahun 1996 menyatakan bahwa seseorang dengan right wing authoritarian tinggi sangat mungkin akan berprasangka. Dalam hal ini, hasil penelitian menunjukan bahwa submissive sebagai bagian dari salah satu dimensi right wing authoritarian ditemukan berpengaruh secara signifikan terhadap prasangka, maka dapat dikatakan bahwa individu dengan tingkat submission yang tinggi yaitu mereka yang relatif patuh kepada orang-orang yang dianggap sebagai otoritas yang sah cenderung untuk berprasangka (Altemeyer, 2004).

Temuan ini juga membuktikan bahwa otoritas yang dianggap sah atau dapat diartikan sebagai pemimpin menjadi sangat berpengaruh terhadap sikap berprasangka seseorang kepada agama tertentu (karena dependent variabel dalam penelitian ini terkait agama lain yaitu non muslim). Pandangan terhadap pemimpin tersebut seolah menimbulkan pola pikir yang rasional maupun irrasional. Pandangan menjadi sangat rasional ketika seseorang yang submission membela dan membenarkan apa yang dilakukan pemimpinnya. Akan tetapi, pandangan menjadi irrasional ketika seseorang yang subimisson membela dan membenarkan pemimpimnya tanpa didahului dengan proses berfikir yang logis, empiris dan adil. Dapat disimpulkan bahwa mereka yang memiliki tingkat submission yang tinggi cenderung untuk berprasangka kepada orang lain yang memiliki keyakinan berbeda disebabkan karena tinggat ketaatan yang tinggi kepada pihak yang pandang memiliki otoritas atau seorang pemimpin.

Selanjutnya dalam konteks religious orientation ditemukan bahwa orientasi ekstrinsik adalah dimensi yang paling berpengaruh secara positif dan signifikan terhadap prasangka antar agama. Hal ini sejalan dengan penelitian yang dilakukan oleh Allport dan Ross (1967) yang mengemukakan bahwa religious orientation seseorang merupakan faktor penting dalam hubungan antara agama 
dengan prasangka. Bahkan hal ini diperkuat dengan penelitian Duck dan Hunsberger (1999) yang menjelaskan bahwa orientasi ekstrinsik berpengaruh secara signifikan terhadap prasangka. Artinya apabila disimpulkan bahwa mereka yang memiliki tingkat orientasi ekstrinsik yang tinggi cenderung untuk berprasangka kepada orang lain yang memiliki keyakinan berbeda disebabkan karena mereka menggunakan agamanya untuk motif mendapatkan keuntungan sosial.

Adapun dalam konteks identitas sosial ditemukan bahwa sense of belonging adalah dimensi yang paling berpengaruh secara positif dan signifikan terhadap prasangka antar agama. Artinya apabila disimpulkan bahwa mereka yang memiliki tingkat sense of belonging yang tinggi cenderung untuk berprasangka kepada orang lain yang memiliki keyakinan berbeda disebabkan karena berkomitmen anggota untuk kelompok dan merasa bagian dari kelompok keagamaan tertentu.

Dalam penelitian ini juga terdapat beberapa variabel yang tidak memiliki pengaruh yang signifikan terhadap prasangka. Hal ini terkadang menjadi pertentangan dengan penelitian terdahulu. Adapun variabel yang terbukti tidak memiliki pengaruh terhadap prasangka antara lain, agression, conventionalism, intrinsik, categorization dan positive attitude.

Hasil penelitian menunjukan bahwa tidak ada pengaruh yang signifikan dari variabel agression dan conventionalism. Hasil penelitian ini tidak sesuai dengan penelitian menunjukkan bahwa right wing authoritarian dapat berhubungan dengan berbagai bentuk prasangka (Hogg \& Cooper, 2007). Tidak hanya itu right wing authoriatarian juga disebut sebagai "prediktor kuat" pada prasangka (Laythe, Finkel, \& Kirkpatrick, 2005).

Selanjutnya, variabel religious orientation dengan dimensi intrinsik memiliki pengaruh yang tidak signifikan terhadap prasangka. Hal ini sejalan dengan penelitian yang dilakukan oleh Allport dan Ross (1967) yang mengemukakan bahwa orientasi intrinsik tidak berpengaruh terhadap prasangka. Artinya, tidak ada pengaruh yang signifikan antara seseorang individu yang menemukan motif utama mereka dalam agama serta segala tingkah lakunya selaras dengan keyakinan dengan prasangka yang didasari latar belakang agama yang berbeda.

Kemudian, variabel lain yang tidak berpengaruh terhadap prasangka adalah categorization dan positive attitude yang merupakan bagian dari social identity. Hal ini pun tidak sesuai dalam penelitian yang dilakukan oleh Brown (1995) yang menemukan bahwa identitas sosial yang terancam dapat membentuk seseorang untuk bersikap prasangka. Perlu diketahui bahwa berdasarkan data proporsi varian menunjukan nilai $\mathrm{R}$ square change sebesar $4,8 \%$ yang dapat diartikan bahwa variabel categorization memberikan kontribusi sebesar $4.7 \%$ (nilai kontribusi variabel yang cukup besar dalam penelitian ini) terhadap variabel prasangka, akan tetapi variabel categorization tidak berpengaruh terhadap prasangka. Berdasarkan temuan ini maka dapat disimpulkan bahwa saat dilakukan analisis tidak ada interaksi dengan variabel lain sehingga menyebabkan nilai kontribusi $\mathrm{R}$ square change besar. Selanjutnya data yang menunjukan tidak ada pengaruh categorization terhadap prasangka disebabkan karena ada interaksi antara variabel categorization dengan variabel lain diluar prasangka. 
Adapun berdasarkan hasil penelitian yang dilakukan, penelitian ini tentunya memiliki keterbatasan yang juga mempengaruhi hasil penelitian, misalnya saja pemilihan subjek penelitian yang pada penelitian ini subjek penelitiannya merupakan mahasiswa UIN Syarif Hidayatullah Jakarta. Harapan awal memilih mahasiswa karena mahasiswa dianggap sebagai gambaran kecil dari masyarakat, dengan begitu sampel mahasiswa sudah menggambarkan apa yang ada di masyarakat. Keterbatasan selanjutnya adalah tema dalam penelitian ini yang berhubungan dengan agama memungkinkan sampel tidak menjawab butir-butir penyatan yang sangat menggambarkan diri dari tiap sampel. Walaupun pada saat penelitian, penulis sudah menjamin untuk menjaga kerahasiaan dari tiap jawaban yang dijawab sampel. Keterbatasan lainnya adalah pemilihan sampel yang kurang mewakili tiap kelompok keagamaan. Pemilihan sampel yang seluruhnya dari mahasiswa UIN Syarif Hidayatullah Jakarta menimbulkan anggapan bahwa pada penelitian kali ini hanya mewakili suatu kelompok agama saja yaitu agama islam. Hal ini dikarenakan seluruh mahasiswa dipastikan beragama islam.

Apabila melihat hasil dan pembahasan di atas, dapat terlihat dinamika dalam penelitian yang telah dilakukan. Dinamika tersebut menjelaskan bahwa seseorang yang berprasangka dipengaruhi oleh kepribadian dan pandangan dirinya terhadap kelompok. Jadi, dapat disimpulkan bahwa seseorang yang memiliki ketertundukan yang tinggi terhadap pihak otoritas, orientasi keagamaan yang bermotif mendapatkan keuntungan sosial dan perasaan memiliki kelompok yang tinggi berpengaruh terhadap prasangka terhadap seseorang yang memiliki latar agama yang berbeda.

Penelitian ini menjadi gambaran besar bagaimana konflik agama yang akhirakhir ini muncul di indonesia. Temuan dalam penelitian ini membuktikan bahwa konflik agama yang terjadi di indonesia sangat erat hubungannya dengan gambaran masyarakat indonesia yang memandang pihak otoritas atau pemimpin memiliki pengaruh besar dalam mempengaruhi sikap seseorang dalam hidup beragama. Selain itu, dalam menjalankan keagamaannya, seseorang yang hanya mencari keuntungan sosial terbukti lebih berprasangka terhadap seseorang yang memiliki latar belakang agama yang berbeda. Penelitian juga menunjukan bahwa masyarakat indonesia memiliki sangat dipengaruhi rasa memiliki kelompok yang tinggi yang memungkinkan seseorang dapat dengan cepat ikut dalam konflik agama dikarenakan rasa memiliki kelompok agama yang tinggi.

Penelitian ini menggunakan teknik sampling non probability dengan meyebar kuisioner secara langsung secara accidental karena situasi yang tidak memungkinkan untuk melakukan penelitian yang idealnya dalam penelitian ini menggunakan teknik random sampling. Oleh karena itu, peneliti selanjutnya diharapkan dengan data mahasiwa yang lengkap dapat menggunakan teknik random sampling agar bisa mendapatkan data yang lebih valid. Dalam penelitian ini, sampel yang digunakan adalah mahasiswa dimana prasangka antar agama menghasilkan pengaruh yang terbilang tidak besar, penulis menyarankan agar penelitian selanjutnya menggunakan sampel lain selain mahasiswa. Variasi sampel yang berbeda dapat digunakan seperti organisasi keagamaan tertentu, kelompok ibadah tertentu (seperti, anggota majelis tertentu atau anggota gereja tertentu), sehingga mendapatkan hasil yang lebih bervariasi dan dapat dijadikan pembanding bagi penelitian ini. Selain itu mengingat keterbatasan jumlah sampel 
yang hanya 200, peneliti sangat disarankan pada penelitian selanjutnya menambahkan jumlah sampel untuk melihat hasil penelitian yang lebih menggambarkan populasi penelitian ini.

\section{Saran}

Penulis menyarankan dalam penelitian selanjutnya mencari faktor-faktor lain yang dapat mempengaruhi prasangka dikarenakan sumbangan variabel yang digunakan terhadap prasangka hanya sebesar $17.5 \%$ dan sisanya $82.5 \%$ dipengaruhi faktor lain. Hal ini bertujuan untuk mendapatkan pengetahuan yang lebih mengenai prasangka. Kemudian penelitian ini hanya mengikutsertakan sampel para mahasiswa dengan agama islam, disarankan pada penelitian selanjutnya untuk menggunakan sampel dengan agama diluar islam. Hal ini agar terlihat pengaruh pada tiap agama mempengaruhi seseorang dalam berprasagka. Selanjutnya dalam penelitian ini, sampel yang digunakan adalah mahasiswa dimana prasangka antar agama menghasilkan pengaruh yang terbilang tidak besar, penulis menyarankan agar penelitian selanjutnya menggunakan sampel lain selain mahasiswa. Variasi sampel yang berbeda dapat digunakan seperti organisasi keagamaan tertentu, kelompok ibadah tertentu (seperti, anggota majelis tertentu atau anggota gereja tertentu), sehingga mendapatkan hasil yang lebih bervariasi dan dapat dijadikan pembanding bagi penelitian ini. Selain itu mengingat keterbatasan jumlah sampel yang hanya 200, sangat disarankan pada penelitian selanjutnya menambahkan jumlah sampel untuk melihat hasil penelitian yang lebih menggambarkan populasi penelitian ini.

\section{DAFTAR PUSTAKA}

Adorno, T. W., Brunswik, e. F., Levinson, D. J., \& Sanfort, R. N. (1950). The authoritarian personality. The Norton Library.

Akrami, N. (2005). Prejudice: The interplay of personality, cognition and social psychology. Dissertation, The degree of doctor of faculty of social sciences in uppsala university.

Ali, D. J. (2013). Menjadi indonesia tanpa diskriminasi. Jakarta: PT Gramedia Pustaka Utama. Allport, G. W., \& Ross, J. M. (1967). Personal religious orientatin and prejudice. Journal of Personality and Social Psychology. 5(4):432-43.

Altemeyer, B. (1996). The authoritarian specter. London: Harvard University Press.

Altemeyer, B. (2004). Highly dominating, highly authoritarian. The Journal of Social Psychology, 144(4):421-47.

Altemeyer, B. (2006). The authoritarians. Winnipeg: Department of Psychology University of Manitoba.

Brown, R. (1995). Prejudice its social psychology. (H. P. Soetjipto, \& S. M. Soetjipto, Penerj.) Massachusetts: Blackwell Publisher Inc.,.

Brown, R. (2010). Prejudice its social psychology (2nd ed.). Massachusetts: Wiley-Blackwell. Childs, C. E. (2011). Right wing authoritarianism and prejudice. Thesis. The degree master of arts in the Ball State University. 
Denney. (2008). Relationships between religion and prejudice. Thesis. The degree of pyschology in Georgia State University.

Feitosa, J., Salas, E., \& Salazar, M. R. (2012). Social identity: Clarifying its dimensions across cultures. Psychological Topics, 21(3) 527-548.

Francis, L. J., Jewell, A., \& Robbins, M. (2010). The relationship between religious orientation, personality and purpose in life among an older methodist sample. Mental Health, Religion \& Culture, 13(10) 777-791.

Funke, F. (2005). The dimensionality of right-wing authoritarianism: Lessons from the dilemma between theory. Political Psychology, 26 (2) 195-218.

Herek, G. M. (1987). Religious orientation and prejudice: A comparison of racial and sexual attitudes. Personality and Social Psychology Bulletin, 13(1) $34-44$.

Hogg, M. A., \& Cooper, J. (2007). The SAGE handbook of social psychology. New York: Sage Publication Ltd.

Hogg, M. A., \& Terry, D. J. (2000). Social identity and self-categorization processes in organizational contexts. The Academy of Management Review, 25(1) 121-140.

Hunsberger, B., \& Duck, R. J. (1999). Religious orientation and prejudice: The role of religious proscription, right-wing. The International Journal for the Psychology of Religion, 9(3) 157- 179.

Jennings, J. (2014). The prejudice paradox: How religious motivations explain the complex relationship between religion and prejudice. Temple University.

Laythe, B., Finkel, D., \& Kirkpatrick, L. A. (2005). Predicting prejudice from religious fundamentalism and right-wing authoritarianism: A multipleregression approach . Journal of Scientific Study of Religion, 40(1) 1-10.

Merz, L. A., \& Pearlin, L. I., (1957) The influence of information on three dimensions of prejudice toward negroes. Oxford Journals, 35(4) 344-351

Plous, S. (2003). The Psychology of prejudice, stereotyping, and discrimination. New York: McGraw- Hill.

Streib, H., \& Klein, C. (2014). Religious styles predict interreligious prejudice: A study of german adolescents with the religious scema scale. The International Journal for the Psychology of Religion, 24(2) 151-163.

Theodorou, A. E. (2015, December 23). Americans are in the middle of the pack globally when it comes to importance of religion. Diambil kembali dari Pewresearch.org: http://www.pewresearch.org/fact-tank/2015/12/23/ americans-are-in-the-middle-of-the-pack- globally-when-it-comes-toimportance-of-religion/

Zick, A., Küpper, B., \& Hövermann, A. (2011). Intolerance, Prejudice and Discrimination: A European Report. Berlin: Friedrich-Ebert-Stiftung. 